\title{
Posterior column osteotomy plus unilateral cage strutting for correction of lumbosacral fractional curve in degenerative lumbar scoliosis
}

Hui Wang ${ }^{1,2,3}$, Longjie Wang ${ }^{1,2,3}$, Zhuoran Sun ${ }^{1,2,3}$, Shuai Jiang ${ }^{1,2,3}$ and Weishi Li $i^{1,2,3^{*}}$

\begin{abstract}
Background: Inadequate release of the posterior spinal bone elements may hinder the correction of the lumbosacral fractional curve in degenerative lumbar scoliosis, since the lumbosacral junction tends to be particularly rigid and may already be fused into an abnormal position. The purpose of this study was to evaluate the surgical outcome and complications of posterior column osteotomy plus unilateral cage strutting technique on lumbosacral concavity for correction of fractional curve in degenerative lumbar scoliosis patients.

Methods: Thirty-two degenerative lumbar scoliosis patients with lumbosacral fractional curve more than $15^{\circ}$ that were surgically treated by posterior column osteotomy plus unilateral cage strutting technique were retrospectively reviewed. The patients' medical records were reviewed to identify demographic and surgical data, including age, sex, body mass index, back pain, leg pain, Oswestry Disability Index, operation time, blood loss, and instrumentation levels. Radiological data including coronal balance distance, Cobb angle, lumbosacral coronal angle, sagittal vertical axis, lumbar lordosis, and lumbosacral lordotic angle were evaluated before and after surgery. Cage subsidence and bone fusion were evaluated at 2-year follow-up.

Results: All patients underwent the operation successfully; lumbosacral coronal angle changed from preoperative $20.1 \pm 5.3^{\circ}$ to postoperative $5.8 \pm 5.7^{\circ}$, with mean correction of $14.3 \pm 4.4^{\circ}$, and the correction was maintained at 2year follow-up. Cobb's angle and coronal balance distance decreased from preoperative to postoperative; the correction was maintained at 2-year follow-up. Sagittal vertical axis decreased, and lumbar lordosis increased from preoperative to postoperative; the correction was also maintained at 2-year follow-up. Lumbosacral lordotic angle presented no change from preoperative to postoperative and from postoperative to 2-year follow-up. Postoperatively, there were 8 patients with lumbosacral coronal angle more than $10^{\circ}$, they got the similar lumbosacral coronal angle correction, but presented larger preoperative Cobb and lumbosacral coronal angle than the other 24 patients. No cage subsidence was detected; all patients achieved intervertebral bone fusion and inter(Continued on next page)
\end{abstract}

\footnotetext{
*Correspondence: puh3liweishi@163.com

The manuscript submitted does not contain information about medical device(s)/drug(s).

'Orthopaedic Department, Peking University Third Hospital, No 49. North

Garden Street, HaiDian District, Beijing 100191, China

${ }^{2}$ Beijing Key Laboratory of Spinal Disease Research, Beijing, China

Full list of author information is available at the end of the article
}

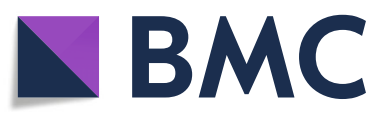

(c) The Author(s). 2020 Open Access This article is licensed under a Creative Commons Attribution 4.0 International License, which permits use, sharing, adaptation, distribution and reproduction in any medium or format, as long as you give appropriate credit to the original author(s) and the source, provide a link to the Creative Commons licence, and indicate if changes were made. The images or other third party material in this article are included in the article's Creative Commons licence, unless indicated otherwise in a credit line to the material. If material is not included in the article's Creative Commons licence and your intended use is not permitted by statutory regulation or exceeds the permitted use, you will need to obtain permission directly from the copyright holder. To view a copy of this licence, visit http://creativecommons.org/licenses/by/4.0/. The Creative Commons Public Domain Dedication waiver (http://creativecommons.org/publicdomain/zero/1.0/) applies to the data made available in this article, unless otherwise stated in a credit line to the data. 
(Continued from previous page)
transverse bone graft fusion at the lumbosacral region at 2-year follow-up.

Conclusion: Posterior column osteotomy plus unilateral cage strutting technique on the lumbosacral concavity facilitate effective correction of the fractional curve in degenerative lumbar scoliosis patients through complete release of dural sac as well as the asymmetrical intervertebral reconstruction by cage.

Keywords: Posterior column osteotomy, Unilateral cage strutting, Lumbosacral fractional curve, Degenerative lumbar scoliosis

\section{Background}

Degenerative lumbar scoliosis (DLS) is a threedimensional disorder that mostly affects the skeletally mature patients; the typical major curve lies in the midlumbar spine; it is always compensated by a distal curve as the body attempts to maintain coronal balance $[1,2]$. Compensatory curve at the lumbosacral region below the major curve is named the fractional curve; the nerve roots on the concave side of the fractional curve are the most frequent radicular pain generators in DLS patients [3-5]. The neurologic symptoms derived from the nerve root compression is strongly correlated with the decision to pursue surgical treatment; spine surgeons must include in surgical planning the symptomatic radicular levels that are related to the fractional curve instead of the major curve [6]. It has been recommended that all fractional curves greater than $15^{\circ}$ must be corrected and included within the instrumentation [7]. If a fractional curve is not addressed properly, the patient is very unlikely to obtain coronal realignment or may experience aggravation of the coronal imbalance; there is a growing body of literature correlating coronal imbalance with a negative effect on patient outcomes [8-11].

Various techniques to correct fractional curve have been described in the literature, including anterior lumbar interbody fusion (ALIF), oblique lumbar interbody fusion (OLIF), posterior or transforaminal lumbar interbody fusion (PLIF or TLIF) [4, 12]. ALIF could achieve better fractional curve improvement but is associated with potential risk of intra-abdominal vascular and visceral injury [13]. OLIF has been proved to correct fractional curve effectively through a minimally invasive incision; it still shares the risk of vascular injury [14]. The posterior insertion of cage into the concavity of the curve through PLIF or TLIF can restore the disc height and achieve lumbosacral curve correction [15]. A laminectomy would be performed medial to the facet in PLIF technique, while bilateral facet joints are preserved. In TLIF technique, the spinal canal is entered via a unilateral laminectomy and inferior facetectomy; the contralateral laminae and facet joint are preserved. Inadequate release of the posterior spinal bone elements in PLIF or TLIF technique may hinder the correction of the lumbosacral curve because the lumbosacral junction tends to be particularly rigid and may already be fused into an abnormal position.

Posterior column osteotomy (PCO) is accomplished by resecting bone and ligaments between the posterior columns of adjacent spinal segments, leaving only the mobile disc anteriorly through which correction is obtained [16-21]. Principal indications for PCO include reducing kyphosis or increasing lordosis on sagittal plane or increasing the flexibility of a stiff scoliosis on the coronal plane to enable correction [22]. It is reasonable to postulate that posterior insertion of cages into the concavity of the curve followed PCO could facilitate more fractional curve correction than PLIF or TLIF, since complete release of the posterior spinal column can be achieved through PCO. However, little evidence is specifically regarding the effect of PCO plus unilateral cage strutting (UCS) in the correction of lumbosacral fractional curve. The purpose of this study is to evaluate the surgical outcome and complications of PCO plus UCS on the lumbosacral concavity for the treatment of fractional curve in DLS.

\section{Materials and methods Patients}

This was a retrospective study and was approved by the Institutional Review Board of our hospital before data collection and analysis. The inclusion criteria are as follows: (1) degenerative lumbar scoliosis with lumbosacral fractional curve more than $15^{\circ}$, which needs correction; (2) the lumbosacral fractional curve was surgically treated by PCO plus UCS technique; (3) minimum follow-up of 2 years; (4) full-spine posterior-anterior (P/ A) and lateral X-ray at pre-op and post-operative. The exclusion criteria are (1) previous surgery for degenerative lumbar disease, (2) underlying diseases that seriously affected the surgical outcomes, and (3) the anatomical identification was difficult to recognize for radiological measurement. From Jan 2014 to Aug 2017, 237 DLS patients were surgically treated in our hospital and were retrospectively reviewed; 32 patients whom met both the inclusion and exclusion criteria were enrolled into this study; the main complaints were pain, walking difficulty, and deformity. 


\section{Data collection}

The patients' medical records were reviewed to identify demographic and surgical data, including age at surgery, sex, body mass index (BMI), back pain (visual analog scale, VAS-back), leg pain (VAS-leg), Oswestry Disability Index (ODI), operation time, blood loss, instrumentation levels, and complications.

Standing $\mathrm{P} / \mathrm{A}$ and lateral radiography was used to evaluate the spine curvature and alignment before surgery, immediately after surgery, at 3 months, and 2 years of follow-up. Coronal balance distance (CBD) was measured as the distance between $\mathrm{C} 7$ plumb line and center sacral vertical line (Fig. 1a). Type of coronal imbalance was evaluated in all the patients: type $\mathrm{A}$, coronal balance distance $(\mathrm{CBD})<3 \mathrm{~cm}$; type $\mathrm{B}, \mathrm{CBD}>3 \mathrm{~cm}$ and $\mathrm{C} 7 \mathrm{PL}$ shifts to the concave side of the curve; Ttype $\mathrm{C}, \mathrm{CBD}>$ $3 \mathrm{~cm}$ and C7PL shifts to the convex side of the curve [23].

Cobb's angle was measured using lines projected from the upper border of the most tilted vertebra above and lower border of the most tilted vertebra within the main curve. Lumbosacral coronal angle (LSCA) was measured using lines projected from the upper border of L4 and upper border of S1 on P/A X-ray (Fig. 1a).

Sagittal vertical axis (SVA) was the distance from C7 plumb line to the perpendicular line drawn from superior posterior endplate of S1. Lumbar lordosis (LL) was measured from upper endplate of L1 to upper endplate of S1. Lumbosacral lordotic angle (LSLA) was measured using lines projected from the upper border of L4 and upper border of S1 on lateral X-ray (Fig. 1b).

Cage subsidence was assessed utilizing lumbar spine CT taken at 2-year postoperatively; it was defined as $2 \mathrm{~mm}$ of cage settlement into the vertebral body (Fig. 2). Assessment of radiological bone fusion at follow-up was based on the presence of trabecular bone bridging at the osteotomy site according to Bridwell et al. [24].

\section{Surgical procedure}

Under general anesthesia, all patients were placed in a prone position on a radiolucent table. A posterior midline incision was made for conventional exposure. Pedicle screws were inserted according to the surgical planning. PCO plus UCS was first performed within the lumbosacral region: The posterior elements that include the spinous process, bilateral laminae, bilateral pars interarticularis, bilateral inferior facet joints, and the medial and superior aspects of the subjacent superior facet joints were removed. The intervertebral foramen was explored; both the exiting nerve roots and the walking nerve roots were exposed and protected. An incision was made through the anulus; the degenerated nucleus pulposus and the cartilaginous endplate were removed by osteotome and rongeur. This procedure was

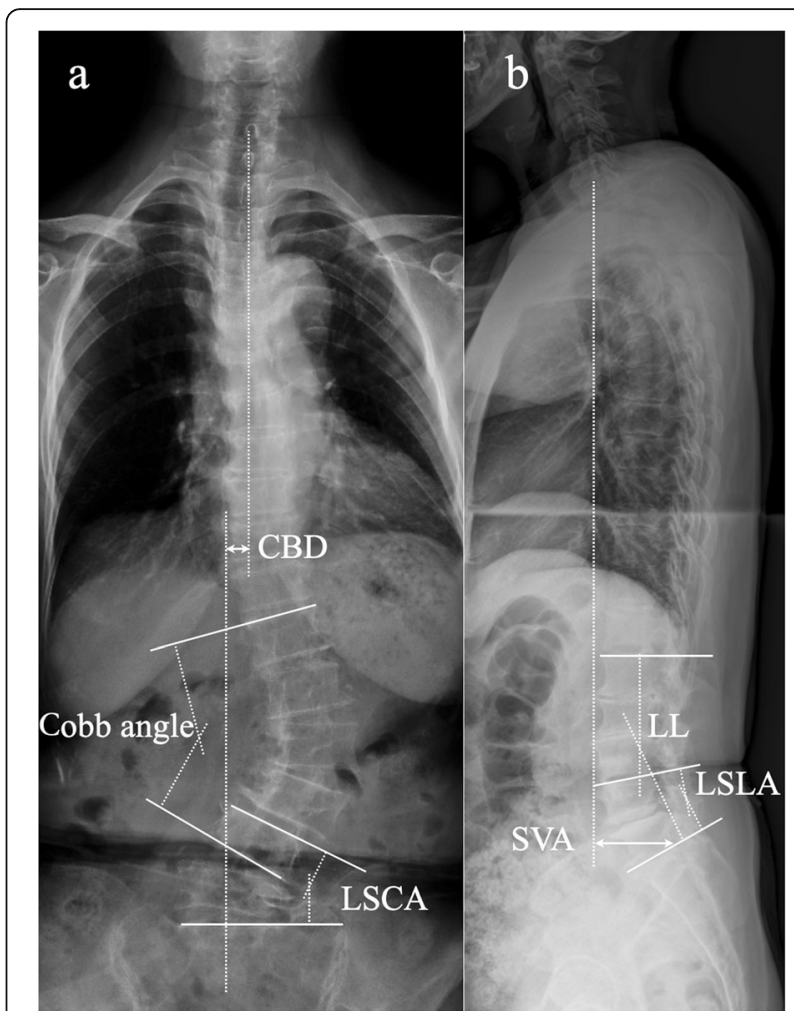

Fig. 1 Schematic diagram of measured coronal and sagittal spinal parameters, including coronal balance distance, Cobb's angle, lumbosacral coronal angle (a), sagittal vertical axis, lumbar lordosis, lumbosacral lordotic angle (b)

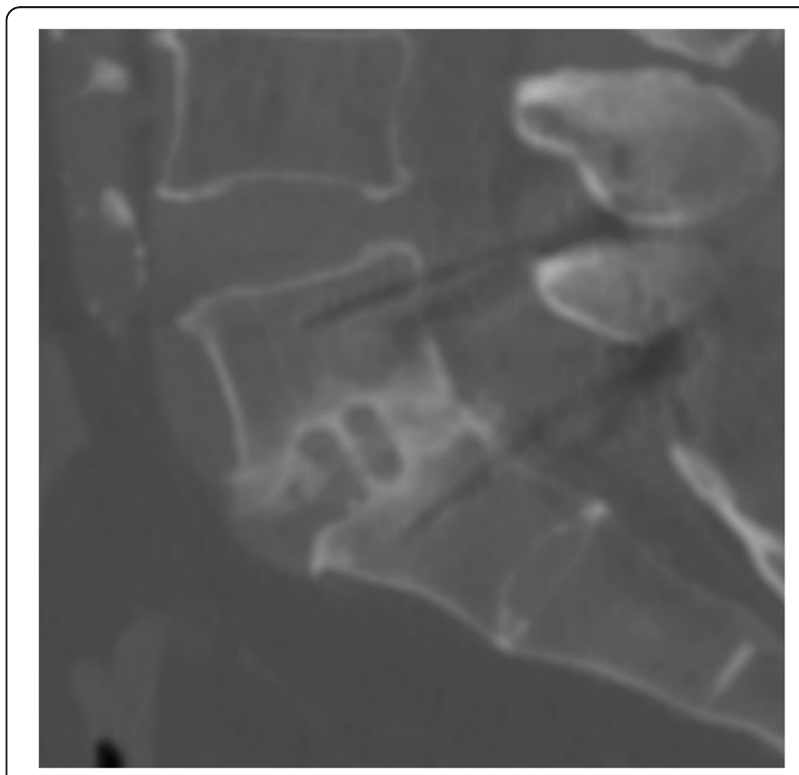

Fig. 2 Cage subsidence is measured as $2 \mathrm{~mm}$ of cage settlement into the vertebral body 
performed bilaterally. On the concave side, the smallest reamer was horizontally inserted into the narrowed disc space and rotated $90^{\circ}$, thereby restoring the disc height and reducing the compensatory scoliosis. The maneuver was repeated using a larger reamer, further enlarging the disc space. A distractor was placed between the pedicle screws on the concave side of the lumbosacral curve; a lordotic-shaped cage filling with autologous bone graft was impacted into the disc space; the unilateral cage serves to maintain the coronal curve correction that had been obtained. The contralateral disc space on the convexity was packed with large amount of autologous bone. After the PCO plus UCS had been performed, the remainder of the procedure within the major curve was carried out in the usual fashion. Prior to securing the rods to the pedicle screws, a compressive force was applied to the screws bilaterally; the force applied on the convex side was greater at the PCO plus UCS level. Inter-transverse bone graft fusion was then performed around the surgical level.

\section{Statistical analysis}

Data were analyzed using the Statistical Product and Service Solutions software (version 13; SPSS, Chicago, IL). Continuous variables were measured as mean \pm standard deviation, and categorical variables were expressed as frequency or percentages. An independent $t$ test was used to analyze the difference of continuous variables. An $x^{2}$ analysis and Fisher's exact test were used to examine the differences among categorical variables. Paired $t$ test was used to analyze the difference of continuous variable between preoperative and postoperative, and between 2-year follow-up and postoperative separately. Variable with $p$ values smaller than 0.05 was considered to be of significant difference.

\section{Result}

All patients underwent the operation successfully, 3 males and 29 females, mean age at surgery was $62.2 \pm$ 7.7 years, and BMI was $25.6 \pm 2.4 \mathrm{~kg} / \mathrm{m}^{2}$. The PCO plus UCS was performed at L4-5 in 22 patients and at L5-S1 in 10 patients. Lower instrumented vertebrae (LIV) at L5 in 22 patients, at $\mathrm{S} 1$ in 10 patients, mean instrumentation level was $7.1 \pm 1.6$, mean surgery time was $299 \pm$ $43 \mathrm{~min}$, and mean blood loss was $1088 \pm 295 \mathrm{~mL}$. All the patients got back pain and leg pain alleviation and neurological function improvement at two-year followup (Table 1).

LSCA was changed from preoperative $20.1 \pm 5.3^{\circ}$ to postoperative $5.8 \pm 5.7^{\circ}$, with mean correction of $14.3 \pm$ $4.4^{\circ}$, and the correction was maintained at 2-year followup. Cobb's angle and CBD were decreased from preoperative to postoperative; the correction was maintained at 2-year follow-up. SVA was decreased, and LL
Table 1 General information of the patients

\begin{tabular}{|c|c|}
\hline No. of cases & 32 \\
\hline Age at surgery (years) & $62.2 \pm 7.7$ \\
\hline Gender (male/female) & $3 / 29$ \\
\hline BMI $\left(\mathrm{kg} / \mathrm{m}^{2}\right)$ & $25.6 \pm 2.4$ \\
\hline \multicolumn{2}{|l|}{ Coronal imbalance types } \\
\hline Type A & 16 \\
\hline Type B & 9 \\
\hline Type C & 7 \\
\hline \multicolumn{2}{|l|}{ PCO plus UCS } \\
\hline$\llcorner 4-5$ & 22 \\
\hline L5-S1 & 10 \\
\hline LIV (L5/S1) & $22 / 10$ \\
\hline No. of instrumentation levels & $7.1 \pm 1.6$ \\
\hline Surgery time (min) & $299 \pm 43$ \\
\hline Estimated blood loss (mL) & $1088 \pm 295$ \\
\hline \multicolumn{2}{|l|}{ VAS-back } \\
\hline Preoperative & $5.9 \pm 2.1$ \\
\hline Two-year follow-up & $1.4 \pm 0.7$ \\
\hline Paired $t$ test & $t=12.984, p<0.001$ \\
\hline \multicolumn{2}{|l|}{ VAS-leg } \\
\hline Preoperative & $4.7 \pm 2.8$ \\
\hline Two-year follow-up & $1.2 \pm 0.6$ \\
\hline Paired $t$ test & $t=6.785, p<0.001$ \\
\hline \multicolumn{2}{|l|}{ ODI } \\
\hline Preoperative & $28.1 \pm 9.1$ \\
\hline Two-year follow-up & $6.4 \pm 1.7$ \\
\hline Paired $t$ test & $t=11.555, p<0.001$ \\
\hline
\end{tabular}

Mean values are presented as \pm standard deviation

$B M I$ body mass index, $P C O$ posterior column osteotomy, UCS unilateral cage strutting, LIV lower instrumented vertebrae, VAS visual analog scale, ODI Oswestry disability index

was increased from preoperative to postoperative; the correction was also maintained at 2-year follow-up. LSLA presented no change from preoperative to postoperative and from postoperative to 2-year follow-up (Table 2) (Fig. 3).

Postoperatively, there were 8 patients with LSCA more than $10^{\circ}$ and were enrolled into the LSCA study group; the other 24 patients were enrolled into LSCA control group. Preoperative Cobb and preoperative LSCA were larger in LSCA study group than those in LSCA control group; no difference was detected in preoperative LSCA, CBD change, Cobb change, LSCA change, Cobb change-CBD change between two sub-groups. No difference was detected in change of VAS-back, VAS-leg, and ODI between the two sub-groups (Table 3).

No cage subsidence was detected; all patients achieved intervertebral bone fusion and inter-transverse bone 
Table 2 Improvement of radiographic parameters from preoperative to follow-up

\begin{tabular}{lllllll}
\hline & CBD & Cobb & LSCA & SVA & LL & LSLA \\
\hline Preoperative & $22.1 \pm 15.0$ & $34.1 \pm 11.4$ & $20.1 \pm 5.3$ & $48.5 \pm 50.7$ & $-19.9 \pm 16.7$ & $-27.9 \pm 12.6$ \\
Postoperative & $16.4 \pm 10.7$ & $8.5 \pm 8.2$ & $5.8 \pm 5.7$ & $23.8 \pm 26.8$ & $-27.1 \pm 15.4$ & $-23.7 \pm 8.3$ \\
Change (post-pre) & $8.1 \pm 16.1$ & $25.6 \pm 9.9$ & $14.3 \pm 4.4$ & $25.0 \pm 44.0$ & $7.1 \pm 1.3$ & $-4.1 \pm 10.5$ \\
Paired $t$ test & $t=2.817$, & $t=14.500$, & $t=18.146$, & $t=3.212$, & $t=2.955$, & $t=1.132$, \\
& $p=0.008$ & $p<0.001$ & $p<0.001$ & $p=0.003$ & $p=0.006$ & $p=0.266$ \\
Two-year FU & $11.8 \pm 8.7$ & $8.7 \pm 8.6$ & $5.8 \pm 5.7$ & $29.2 \pm 35.0$ & $-24.2 \pm 18.4$ & $-22.6 \pm 8.1$ \\
Change (follow-post) & $2.2 \pm 8.3$ & $0.2 \pm 0.7$ & $0.1 \pm 0.4$ & $5.7 \pm 21.5$ & $-2.7 \pm 2.9$ & $-1.1 \pm 1.3$ \\
Paired $t$ test & $t=1.514$, & $t=-1.561$, & $t=-0.373$, & $t=-1.495$, & $t=-0.524$, & $t=518$, \\
& $p=0.140$ & $p=0.129$ & $p=0.712$ & $p=0.145$ & $p=0.604$ & $p=0.606$ \\
\hline
\end{tabular}

Mean values are presented as \pm standard deviation

CBD coronal balance distance, $L S C A$ lumbosacral coronal angle, SVA sagittal vertical axis, $L L$ indicates lumbar lordosis, $L S L A$ lumbosacral sagittal angle, FU indicates follow-up

graft fusion at the lumbosacral region at final follow-up. Cerebrospinal fluid leak occurred in 1 patient (PCO plus UCS at L4-5), she received prolonged drainage, and no neurological damage was detected. Proximal junctional kyphosis (PJK) was detected in 3 patients at 2-year follow-up, they presented no symptom, and no intervention was required at that time.

\section{Discussion}

In the current study, we prove that PCO plus UCS on the lumbosacral concavity facilitate effective correction of the fractional curve in DLS patients through complete release of dural sac as well as the asymmetrical intervertebral reconstruction by cage. The mean correction of fractional curve by PCO plus UCS was $14.3^{\circ}$; it was larger than the report in the previous literature $\left(10^{\circ}\right)$ [4]. According to the classification system of anatomically based spinal osteotomy by Schwab et al., the PCO procedure is classified as grade II osteotomy, which is describe as both inferior and superior facets of an articulation at a given spinal segment resected, as well as the ligamentum flavum; other posterior elements of the vertebra including the lamina, or the spinous processes, may also be resected [25]. PCO plus UCS technique not only includes the osteotomy in the posterior column of the spine, but also facilitates anterior asymmetrical intervertebral reconstruction by cage followed removal of disc; we suggest that it should be classified as grade II+ osteotomy.

There are three technical points of PCO plus UCS for lumbosacral curve correction. First, the posterior elements that include the spinous process, bilateral lamina, and the adjacent facet joints were completely removed. This degree of bone resection allows for the involved nerve roots to be completely decompressed in addition to a dorsal release of the coronal deformity and passive deformity correction [26]. When compared to the TLIF and PLIF, PCO could effectively prevent the nerve root injury on the convex side of the lumbosacral curve in the procedure of pedicle screw-rod compression. Second, using sequential reamer on the concave side, disc height could be improved, and fractional curve correction can be anticipated. Great care should be taken to preserve the vertebral bone endplates for preventing cage subsidence; this is particularly important in the setting of osteoporosis. Third, concave distraction was the

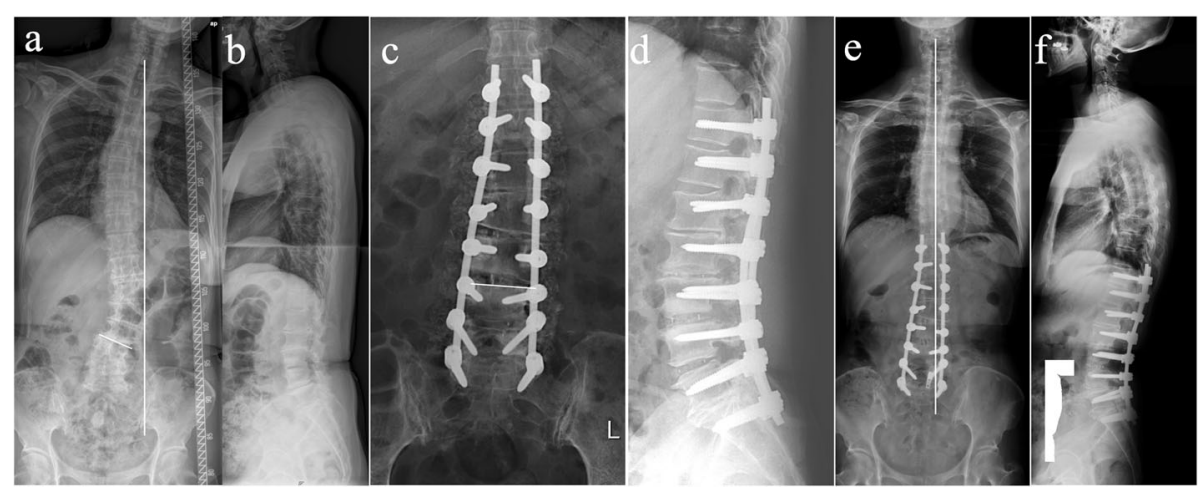

Fig. 3 The patient, male, 63 years old. Preoperative Cobb's angle was $31^{\circ}$, CBD was $47 \mathrm{~mm}$, LSCA was $22^{\circ}$, SVA was $30 \mathrm{~mm}$, LL was $26^{\circ}$, and LSLA was $15^{\circ}$ (a and $\mathbf{b}$ ). PCO plus UCS was performed at the left side of L4-5 (lumbosacral concavity). At postoperative, Cobb's angle was $8^{\circ}$, LSCA was $7^{\circ}$ (c and d). At 2-year follow-up, Cobb's angle was $7^{\circ}$, CBD was $18 \mathrm{~mm}$, LSCA was $7^{\circ}$, SVA was $14 \mathrm{~mm}$, LL was $34^{\circ}$, and LSLA was $24^{\circ}$ (e and $\mathbf{f}$ ) 
Table 3 Comparison of radiographic data between LSCA study and control groups

\begin{tabular}{|c|c|c|c|c|}
\hline & LSCA study group & LSCA control group & Statistics & $p$ \\
\hline Preoperative CBD & $24.4 \pm 14.8$ & $21.2 \pm 15.3$ & -0.501 & 0.620 \\
\hline Preoperative Cobb & $42.4 \pm 8.2$ & $31.3 \pm 11.1$ & -2.590 & 0.015 \\
\hline Preoperative LSCA & $27.5 \pm 4.0$ & $17.6 \pm 2.9$ & -7.501 & 0.001 \\
\hline CBD change & $10.7 \pm 21.3$ & $7.1 \pm 14.4$ & -0.543 & 0.591 \\
\hline Cobb change & $24.1 \pm 7.3$ & $26.1 \pm 10.8$ & 0.460 & 0.649 \\
\hline LSCA change & $13.8 \pm 7.3$ & $14.4 \pm 3.1$ & 0.294 & 0.771 \\
\hline Cobb change-LSCA change & $10.3 \pm 3.1$ & $11.6 \pm 10.4$ & 0.358 & 0.723 \\
\hline VAS-back change & $4.7 \pm 1.3$ & $3.8 \pm 1.8$ & -1.265 & 0.216 \\
\hline VAS-leg change & $3.1 \pm 3.5$ & $3.6 \pm 2.7$ & 0.414 & 0.682 \\
\hline ODI change & $22.5 \pm 15.3$ & $17.7 \pm 10.4$ & -0.988 & 0.331 \\
\hline
\end{tabular}

Mean values are presented as \pm standard deviation

$C B D$ indicates coronal balance distance, $L S C A$ lumbosacral coronal angle, VAS visual analog scale, ODI Oswestry disability index

preferred method of correction of the lumbosacral fractional curve over convex compression for its beneficial effects on the foraminal compression [27]. In this series, distraction of pedicle screw-rod on the concave side before anterior column support using a cage could partly correct the scoliosis; then, compression on the convex side following cage introduction could further correct the scoliosis; the cage within the concave side may act as a hinge on the coronal plane in this procedure.

Postoperative lumbosacral curve is determined by the amount of fractional curve correction and preoperative fractional curve. In the current study, all patients achieved significant fractional curve correction, but eight patients remained fractional curve more than $10^{\circ}$ at postoperative; these patients presented larger preoperative fractional curve and major curve; the mean fractional curve correction presented no difference when compared to the other patients $\left(13.8^{\circ}\right.$ vs. $\left.14.4^{\circ}\right)$. That is, the greater the coronal Cobb of the major curve, the greater the coronal Cobb of the fractional curve to compensate [3]. Although lumbosacral fractional curve can be effectively corrected by the PCO plus UCS technique, the correction is limited even though circumferential decompression plus unilateral cage strutting were performed; we suggest that it should be incorporated into the consideration of the preoperative surgical planning; complete correction of the fractional curve should not be anticipated for patients with preoperative curve more than $15^{\circ}$.

Both lumbosacral fractional curve correction and major curve correction in the mid-lumbar spine are critical for the postoperative coronal balance; mismatch between them may result in the aggravation of the coronal imbalance at postoperative [11, 28-30]. Wang reported that three patients had worsening of coronal balance due to straightening of the major curve without addressing the fractional curve adequately [15]. Strategies to overcome this include accepting less major curve correction or more dedicated correction of lumbosacral fractional curve [30]. Determining coronal balance intraoperatively is difficult as long cassette radiographs could not be accessed intraoperatively in many medical centers. However, an intraoperative P/A lumbar radiograph can be performed to offer the necessary visualization of lumbosacral curve correction; it could provide the surgeons with the required information to make better judgements on the overall coronal balance achieved, as the correction of major curve in midlumbar spine could be calculated to match for the fractional curve left at intra-operative [27]. Among the eight patients remained postoperative fractional curve more than $10^{\circ}$ in the current study, they all achieved well postoperative coronal balance; the less major curve correction is the most likely reason.

The lumbosacral kyphotic angle slightly decreased from preoperative to postoperative followed PCO plus UCS technique; this finding is opposite to the previous reports, which proved that about $10^{\circ}$ degrees can be corrected per level using PCO to treat a kyphotic deformity [31, 32]. Sanghyun $\mathrm{H}$, et al. demonstrated that surgical level at L4-5, performing TLIF with PCO, and the preoperative kyphotic disc space angle predisposed the patients to achieve angular change more than $10^{\circ}$ degrees sagittally [33]. The most possible explanation may be that, posterior distraction of the lumbosacral concavity through pedicle screw-rod provides direct disc height restoration and scoliosis correction, but may decrease the lordosis inevitably, since it is a kyphosing technique. By using a lordotic rod, the negative impact of the compression on the concave side would be minimized [26].

Although unilateral cage strutting could provide help in correcting the lumbosacral curve, the cage within the concave side might carry much more axial gravity loading than the autologous morserized bone being impacted 
within the convex side, presenting higher risk of postoperative cage subsidence on the concavity, especially in patients with osteoporosis. In the current study, no patient experienced cage migration at two2-year follow- up based on the criteria of $2 \mathrm{~mm}$ of cage settlement into the vertebral body, which is contrary to the above assumption. Two possible explanations may account for it. Firstly, as the interface between implants and vertebral bodies, the endplates play an important role in distributing the compressive load on the vertebral bodies. The endplate with sclerotic changes is more common on the concave side than that on the convex side of the same vertebrae, indicating that the concave side of the vertebrae may present high mechanical impedance to prevent cage subsidence [34]. Secondly, all patients achieved intervertebral bone fusion at the lumbosacral region; they also got inter-transverse bone graft fusion, which may provide additional stability at the lumbosacral region and decrease the risk of cage subsidence.

There are several potential limitations in this study. Retrospective studies suffer from a number of limitations like selection bias, and the sample size was small and from a single center, multicenter study is required to verify the surgical outcome of PCO plus UCS in the treatment of lumbosacral fractional curve in the future.

\section{Conclusion}

PCO plus UCS on the lumbosacral concavity facilitates effective correction of the fractional curve in DLS patients through complete release of dural sac as well as the asymmetrical intervertebral reconstruction by cage.

\section{Acknowledgements}

None

\section{Authors' contributions}

$\sqcup \mathrm{W}$ conceived the project and analyzed the data. All authors contributed towards the interpretation and the collection of the data. All authors wrote and approved the final manuscript.

\section{Funding}

Not applicable

\section{Availability of data and materials}

The data used and analyzed during the current study was available from the corresponding author on reasonable request.

\section{Ethics approval and consent to participate}

All procedures performed in studies involving human participants were in accordance with the ethical standards of the institutional and/or national research committee and with the 1964 Helsinki declaration and its later amendments or comparable ethical standards. For this type of study, the informed consent was waived. This study was approved by Peking University Third Hospital Ethics Committee.

\section{Consent for publication}

Not applicable

\section{Competing interests}

The authors declare that they have no competing interests.

\section{Author details}

'Orthopaedic Department, Peking University Third Hospital, No 49. North Garden Street, HaiDian District, Beijing 100191, China. ${ }^{2}$ Beijing Key Laboratory of Spinal Disease Research, Beijing, China. ${ }^{3}$ Engineering Research Center of Bone and Joint Precision Medicine, Ministry of Education, Beijing, China.

Received: 11 August 2020 Accepted: 6 October 2020

Published online: 20 October 2020

\section{References}

1. Obeid I, Berjano P, Lamartina C. Classification of coronal imbalance in adult scoliosis and spine deformity: a treatment-oriented guideline. Eur Spine J. 2019;28:94-113. https://doi.org/10.1007/s00586-018-5826-3.

2. Bao H, Zhu F, Liu Z. Coronal curvature and spinal imbalance in degenerative lumbar scoliosis: disc degeneration is associated. Spine (Phila Pa 1976). 2014;39:E1441-7. https://doi.org/10.1097/BRS.0000000000000603.

3. Ferrero $E$, Khalifé M, Marie-Hardy L. Do curve characteristics influence stenosis location and occurrence of radicular pain in adult degenerative scoliosis? Spine Deform. 2019;7:472-80. https://doi.org/10.1016/j.jspd.2018. 09.010 .

4. Chou D, Mummaneni P, Anand N. Treatment of the fractional curve of adult scoliosis with circumferential minimally invasive surgery versus traditional open surgery: an analysis of surgical outcomes. Global Spine J. 2018;8:82733. https://doi.org/10.1177/2192568218775069.

5. Campbell PG, Nunley PD. The challenge of the lumbosacral fractional curve in the setting of adult degenerative scoliosis. Neurosurg Clin N Am. 2018;29: 467-74. https://doi.org/10.1016/j.nec.2018.02.004.

6. Hawasli AH, Chang J, Yarbrough CK. Interpedicular height as a predictor of radicular pain in adult degenerative scoliosis. Spine J. 2016;16:1070-8. https://doi.org/10.1016/j.spinee.2016.04.017.

7. Silva FE, Lenke LG. Adult degenerative scoliosis: evaluation and management. Neurosurg Focus. 2010;28:E1. https://doi.org/10.3171/2010.1. FOCUS09271.

8. Acaroglu E, Guler UO, Olgun ZD. European Spine Study Group. Multiple regression analysis of factors affecting health related quality of life in adult spinal deformity. Spine Deform. 2015;3:360-6. https://doi.org/10.1016/j.jspd. 2014.11.004.

9. Koller H, Pfanz C, Meier O. Factors influencing radiographic and clinical outcomes in adult scoliosis surgery: a study of 448 European patients. Eur Spine J. 2016;25:532-48. https://doi.org/10.1007/s00586-015-3898-x.

10. Ploumis A, Liu H, Mehbod AA. A correlation of radiographic and functional measurements in adult degenerative scoliosis. Spine (Phila Pa 1976). 2009; 34:1581-4. https://doi.org/10.1097/BRS.0b013e31819c94cc.

11. Ploumis A, Simpson AK, Cha TD. Coronal spinal balance in adult spine deformity patients with long spinal fusions: a minimum 2-5 year follow-up study. J Spinal Disord Tech. 2015;28:341-7. https://doi.org/10.1097/BSD. Ob013e3182aab2ff.

12. Heary RF, Kumar S, Bono CM. Decision making in adult deformity. Neurosurgery. 2008;63:69-77. https://doi.org/10.1227/01.NEU.0000320426. 59061.79 .

13. Korovessis $P$, Syrimpeis $V$, Tsekouras $V$. Short lumbosacral decompression plus fixation does not change the spinopelvic balance on patients with moderate degenerative spondylolisthesis and associated spinal stenosis. Spine Deform. 2019;7:346-55. https://doi.org/10.1016/j.jspd.2018.08.016.

14. Li JX, Phan K, Mobbs R. Oblique lumbar interbody fusion: technical aspects, operative outcomes, and complications. World Neurosurg. 2017;98:113-23. https://doi.org/10.1016/j.wneu.2016.10.074.

15. Wang MY. Improvement of sagittal balance and lumbar lordosis following less invasive adult spinal deformity surgery with expandable cages and percutaneous instrumentation. J Neurosurg Spine. 2013;18:4-12. https://doi. org/10.3171/2012.9.SPINE111081.

16. Bekmez S, Ozhan M, Olgun ZD. Pedicle subtraction osteotomy versus multiple posterior column osteotomies in severe and rigid neuromuscular scoliosis. Spine (Phila Pa 1976). 2018;43:E905-10. https://doi.org/10.1097/BRS. 0000000000002538.

17. Sze CH, Smith JC, Luhmann SJ. Complications of posterior column osteotomies in the pediatric spinal deformity patient. Spine Deform. 2018;6: 656-61. https://doi.org/10.1016/j.jspd.2018.03.004.

18. Liu H, Yang C, Zheng Z. Comparison of Smith-Petersen osteotomy and pedicle subtraction osteotomy for the correction of thoracolumbar kyphotic deformity in ankylosing spondylitis: a systematic review and meta-analysis. 
Spine (Phila Pa 1976). 2015;40:570e9. https://doi.org/10.1097/BRS. 0000000000000815.

19. Diab MG, Franzone JM, Vitale MG. The role of posterior spinal osteotomies in pediatric spinal deformity surgery: indications and operative technique. J Pediatr Orthop. 2011;31:S88e98. https://doi.org/10.1097/BPO. 0b013e3181f73bd4.

20. Bridwell KH. Decision making regarding Smith-Petersen vs. pedicle subtraction osteotomy vs. vertebral column resection for spinal deformity. Spine (Phila Pa 1976). 2006;31:S171e8. https://doi.org/10.1097/01.brs. 0000231963.72810 .38$.

21. Ghobrial GM, Gjolaj JP. Multilevel posterior column osteotomies for sagittal plane correction in the management of adult degenerative scoliosis. Spine J. 2017;17:S166-7. https://doi.org/10.1016/j.spinee.2017.05.013.

22. Dorward IG, Lenke LG, Stoker GE. Radiographical and clinical outcomes of posterior column osteotomies in spinal deformity correction. Spine (Phila Pa 1976). 2014;39:870-80. https://doi.org/10.1097/BRS.0000000000000302.

23. Bao H, Yan P, Qiu Y. Coronal imbalance in degenerative lumbar scoliosis: prevalence and influence on surgical decision-making for spinal osteotomy. Bone Joint J. 2016;98:1227-33. https://doi.org/10.1302/0301-620X.98B9. 37273.

24. Bridwell $K H$, Lenke $L G, M c E n e r y ~ K W$. Anterior fresh frozen structural allografts in the thoracic and lumbar spine. Spine (Phila Pa 1976). 1995;20: $1410-8$

25. Schwab F, Blondel B, Chay E. The comprehensive anatomical spinal osteotomy classification. Neurosurgery. 2014;74:112-20. https://doi.org/10. 1227/NEU.00000000000001820.

26. Heary RF, Karimi RJ. Correction of lumbar coronal plane deformity using unilateral cage placement. Neurosurg Focus. 2010;28:E10. https://doi.org/10. 3171/2009.12.FOCUS09281

27. Lewis SJ, Keshen SG, Kato S. Risk factors for postoperative coronal balance in adult spinal deformity surgery. Global Spine J. 2018;8:690-7. https://doi. org/10.1177/2192568218764904.

28. Xu L, Chen X, Qiao J. Coronal imbalance after three-column osteotomy in thoracolumbar congenital kyphoscoliosis: incidence and risk factors. Spine (Phila Pa 1976). 2019;44:E99-E106. https://doi.org/10.1097/BRS. 0000000000002773.

29. Plais N, Bao H, Lafage R. The clinical impact of global coronal malalignment is underestimated in adult patients with thoracolumbar scoliosis. Spine Deform. 2020;8:105-13. https://doi.org/10.1007/s43390-020-00046-z.

30. Bao H, Liu Z, Zhang Y. Sequential correction technique to avoid postoperative global coronal decompensation in rigid adult spinal deformity: a technical note and preliminary results. Eur Spine J. 2019;28: 2179-86. https://doi.org/10.1007/s00586-019-06043-9.

31. Dorward IG, Lenke LG. Osteotomies in the posterior-only treatment of complex adult spinal deformity: a comparative review. Neurosurg Focus. 2010;28:E4. https://doi.org/10.3171/2009.12.FOCUS09259.

32. Cho K, Bridwell KH, Lenke LG. Comparison of Smith-Petersen versus pedicle subtraction osteotomy for the correction of fixed sagittal imbalance. Spine (Phila Pa 1976). 2005;30:2030-7. https://doi.org/10.1097/01.brs.0000179085. 92998.ee.

33. Sanghyun $\mathrm{H}$, Seung-Jae $\mathrm{H}$, Ki-Jeong K. Factors for the acquisition of $10^{\circ}$ angular change at the lumbar spine through posterior column osteotomy in adult spinal deformity surgery. Neurosurg Spine. 2018;29:667-73. https:// doi.org/10.3171/2018.5.SPINE1858.

34. Wu H-L, Ding $W-Y$, Shen $Y$. Prevalence of vertebral endplate modic changes in degenerative lumbar scoliosis and its associated factors analysis. Spine. 2012;37:1958-64. https://doi.org/10.1097/BRS.0b013e31825bfb85.

\section{Publisher's Note}

Springer Nature remains neutral with regard to jurisdictional claims in published maps and institutional affiliations.

Ready to submit your research? Choose BMC and benefit from:

- fast, convenient online submission

- thorough peer review by experienced researchers in your field

- rapid publication on acceptance

- support for research data, including large and complex data types

- gold Open Access which fosters wider collaboration and increased citations

- maximum visibility for your research: over $100 \mathrm{M}$ website views per year

At BMC, research is always in progress.

Learn more biomedcentral.com/submissions 